Supporting Information

\title{
A single-component flavoenzyme catalyzed regioselective halogenation of pyrone in the biosynthesis of venemycins
}

Rentai Song, ${ }^{\dagger}$ Haixia Shi,${ }^{\dagger}$ Jing Zhu, ${ }^{\dagger}$ Haoxin Wang ${ }^{*}, \dagger$, Yuemao Shen ${ }^{*},, \neq$

†State Key Laboratory of Microbial Technology, Shandong University, Qingdao, 266237, P. R. China

¥Key Laboratory of Chemical Biology (Ministry of Education), School of Pharmaceutical Sciences, Shandong University, Jinan, Shandong 250012, P. R. China.

*Corresponding authors: wanghaoxin@sdu.edu.cn (H. Wang), yshen@sdu.edu.cn (Y. Shen). 


\section{Contents}

1. General procedures

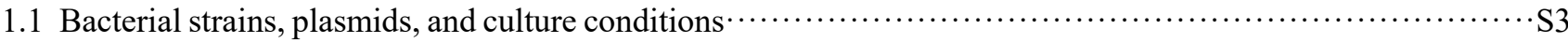

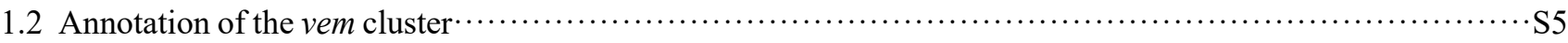

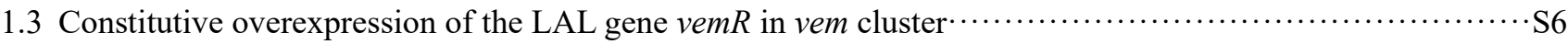

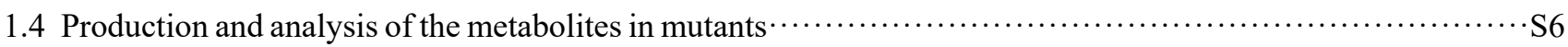

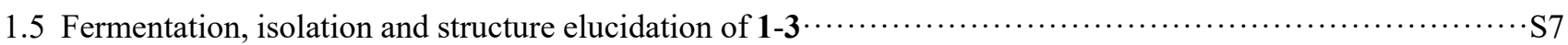

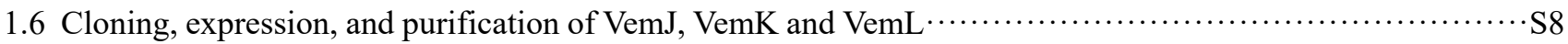

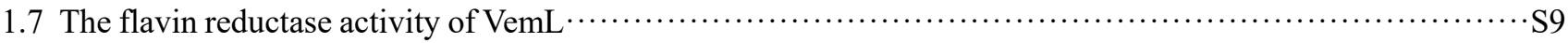

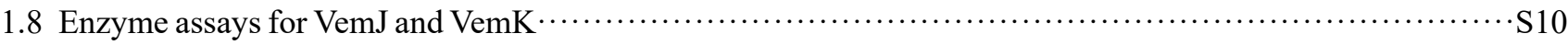

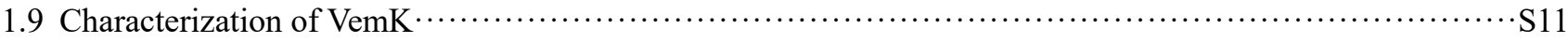

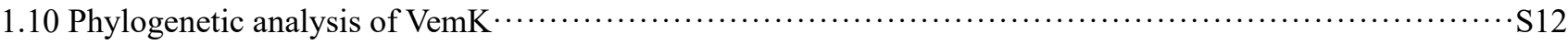

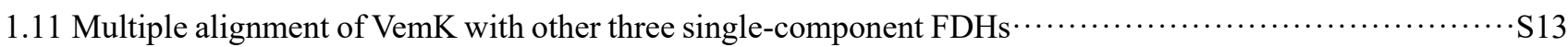

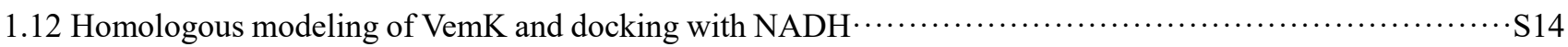

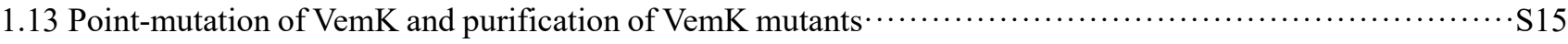

2. NMR and HR ESIMS spectra of compounds $\mathbf{1}-\mathbf{3}$

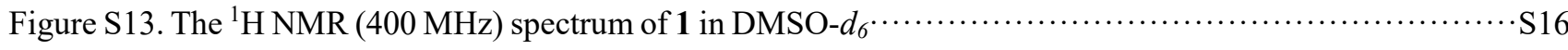

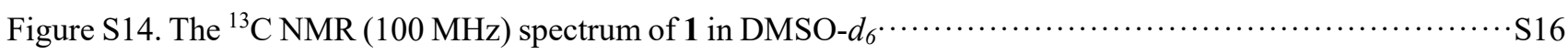

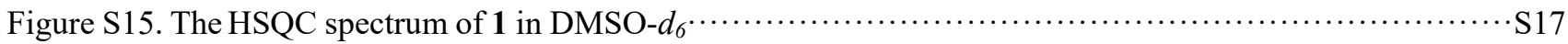

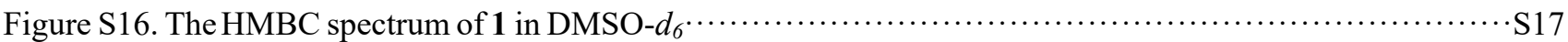

Figure S17. The HRESI mass spectrum of 1 …

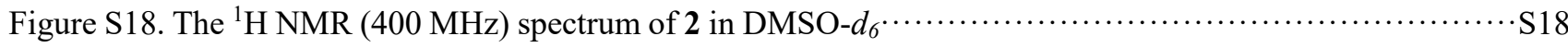

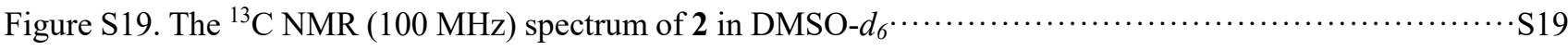

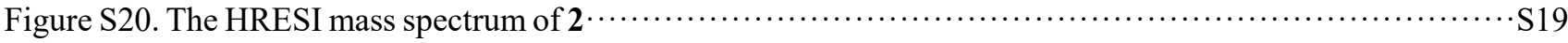

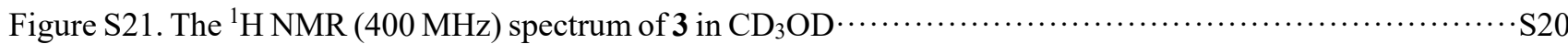

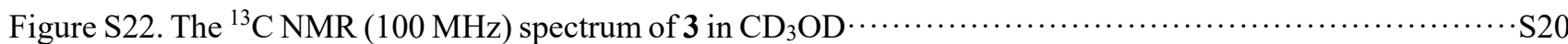

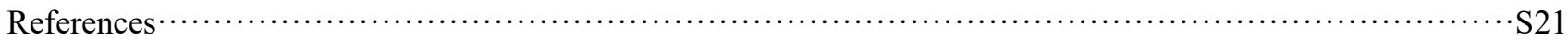




\section{General procedures}

\subsection{Bacterial strains, plasmids, and culture conditions}

Strains and plasmids used in this study are listed in Table S1. All E. coli strains were cultivated in Luria-Bertani (LB) at $37^{\circ} \mathrm{C}$. Streptomyces sp. S006 and its mutants were grown at $37{ }^{\circ} \mathrm{C}$. SFM agar $(2 \%$ D-mannitol, $2 \%$ soybean meal, $1.5 \%$ agar, $\mathrm{pH} 7.2)$ was used for conjugation between E. coli and Streptomyces. YMG broth (10\% malt extract, $4 \%$ glucose, $4 \%$ yeast extract, $\mathrm{pH} 7.2$ ) was used for mycelial growth. Waksman agar ( $30 \%$ glycerol, $0.1 \%$ $\mathrm{K}_{2} \mathrm{HPO}_{4}, 0.05 \% \mathrm{MgSO}_{4} .7 \mathrm{H}_{2} \mathrm{O}, 0.05 \% \mathrm{KCl}, 0.001 \% \mathrm{FeSO}_{4} .7 \mathrm{H}_{2} \mathrm{O}, 0.2 \% \mathrm{NaNO}_{3}, 1.5 \%$ agar, $\mathrm{pH} 7.2$ ), SFM agar, and YMG agar was used for fermentation of Streptmyces sp. S006. The final antibiotic concentrations used for selection were kanamycin $(50 \mu \mathrm{g} / \mathrm{ml})$, chloramphenicol $(12.5 \mu \mathrm{g} / \mathrm{ml})$, and apramycin $(30 \mu \mathrm{g} / \mathrm{ml})$ for E. coli, and nalidixic acid $(25 \mu \mathrm{g} / \mathrm{ml})$, apramycin $(150 \mu \mathrm{g} / \mathrm{mL})$, and thiostrepton $(25 \mu \mathrm{g} / \mathrm{ml})$ for Streptomyces.

Table S1. Bacterial strains and plasmids used in this study.

\begin{tabular}{|c|c|c|}
\hline \multirow{2}{*}{$\frac{\text { Strains/Plasmids }}{\text { Bacterial strains }}$} & \multirow[t]{2}{*}{ Description } & or Sources \\
\hline & & \\
\hline E. coli $\mathrm{DH} 5 \mathrm{a}$ & Plasmid amplification strain & Stratagene \\
\hline E. coli $\mathrm{ET} 12567 / \mathrm{pUZ} 8002$ & Conjugation donor strain & \\
\hline E. coli BL21(DE3) & Protein expression strain & Novagen \\
\hline E. coli $\mathrm{BL} 21(\mathrm{DE} 3) / \mathrm{pGro} 7$ & Protein expression strain & Takara \\
\hline E. coli RIPL & Protein expression strain & Agilent \\
\hline Streptomyces sp. S006 & vem-cluster silent strain & This study \\
\hline Streptomyces sp. S006-LAL & vem-cluster activated strain & This study \\
\hline \multicolumn{3}{|l|}{ Plasmids } \\
\hline pSET152ER* & Constitutive overexpression vector & 2 \\
\hline pSET152ER*-LAL & pSET152ER* containing vemR & This study \\
\hline pET28a & Protein expression vector & Novagen \\
\hline pET28a-vemJ & VemJ protein expression plasmid & This study \\
\hline pET28a-vemK & VemK protein expression plasmid & This study \\
\hline pET28a-vemL & VemL protein expression plasmid & This study \\
\hline pET28a-vemK $(\mathrm{S} 21 \mathrm{~A})$ & VemK protein (serine $_{21}$ mutated into alanine 21 ) expression plasmid & This study \\
\hline pET28a-vemK (E194A) & $\begin{array}{l}\text { VemK protein (glutamic acid }{ }_{194} \text { mutated into alanine }{ }_{194} \text { ) expression } \\
\text { plasmid }\end{array}$ & This study \\
\hline pET28a-vemK (R199A) & $\begin{array}{l}\text { VemK protein (arginine } 199 \text { mutated into alanine }{ }_{199} \text { ) expression } \\
\text { plasmid }\end{array}$ & This study \\
\hline pET28a-vemK (S314A) & VemK protein (serine 314 mutated into alanine 314 ) expression plasmid & This study \\
\hline pET28a-vemK (T315A) & $\begin{array}{l}\text { VemK protein (threonine } 315 \text { mutated into alanine } 315 \text { ) expression } \\
\text { plasmid }\end{array}$ & This study \\
\hline pET28a-vemK (R317A) & $\begin{array}{l}\text { VemK protein (arginine } 317 \text { mutated into alanine }{ }_{317} \text { ) expression } \\
\text { plasmid }\end{array}$ & This study \\
\hline
\end{tabular}


Table S2. Oligos used in this study.

\begin{tabular}{|c|c|}
\hline Primers & Sequences $\left(5^{\prime}-3^{\prime}\right)$ \\
\hline M13-47 & CGCCAGGGTTTTCCCAGTCACGAC \\
\hline LAL-F & CGCCATATGGTGCTGGTCGAGCGGGA \\
\hline LAL-R & GCTCTAGACTAGGGGGAATAGGGGGAGG \\
\hline vemJF & CGCCATATGCCGTCCACTCTCACCGG \\
\hline vemJR & CCCAAGCTTGTTCTCGGCGGGGGTGGAGG \\
\hline vemKF & CGCCATATGCACGGCAAGAATTCCGCCTC \\
\hline vemKR & CCCAAGCTTTCAGTAGTCCGTGGAACCGT \\
\hline vemLF & CGCCATATGTCGCACCAGCGGTACGA \\
\hline vemLR & CCGCTCGAGGGAGATGTAGTCGTAGGACA \\
\hline VemK-F2 & GCCGCGCGGCAGCCATATGCACGGCAAGAATTCCGC \\
\hline VemK-R2 & CGAGTGCGGCCGCAAGCTTTCAGTAGTCCGTGGAACCGT \\
\hline $21 \mathrm{~F}$ & GTGGCGATCCTCGGAGCCGGCATGGCCGGGGGCATGCT \\
\hline $21 \mathrm{R}$ & GCATGCCCCCGGCCATGCCGGCTCCGAGGATCGCCACGTCGT \\
\hline $194 \mathrm{~F}$ & CGCTCGCCGCTCGCGGCCAAGTTCGACCTGCGTGAGAC \\
\hline 194R & GGCCGCGAGCGGCGAGCGGAACC \\
\hline $199 \mathrm{~F}$ & GAGAAGTTCGACCTGGCCGAGACGCCGACGCGTGCCCG \\
\hline 199R & GGCCAGGTCGAACTTCTCCGCGA \\
\hline $314 \mathrm{~F}$ & GTCCGCCCGTGGGTCGCCACCGGCCGGCTCCAGTACTC \\
\hline $314 \mathrm{R}$ & GGCGACCCACGGGCGGACCGACT \\
\hline $315 \mathrm{~F}$ & CGCCCGTGGGTCTCCGCCGGCCGGCTCCAGTACTCGGC \\
\hline $315 \mathrm{R}$ & GGCGGAGACCCACGGGCGGACCG \\
\hline $317 \mathrm{~F}$ & TGGGTCTCCACCGGCGCCCTCCAGTACTCGGCCGAGAC \\
\hline $317 \mathrm{R}$ & GGCGCCGGTGGAGACCCACGGGC \\
\hline
\end{tabular}




\subsection{Annotation of the vem cluster}

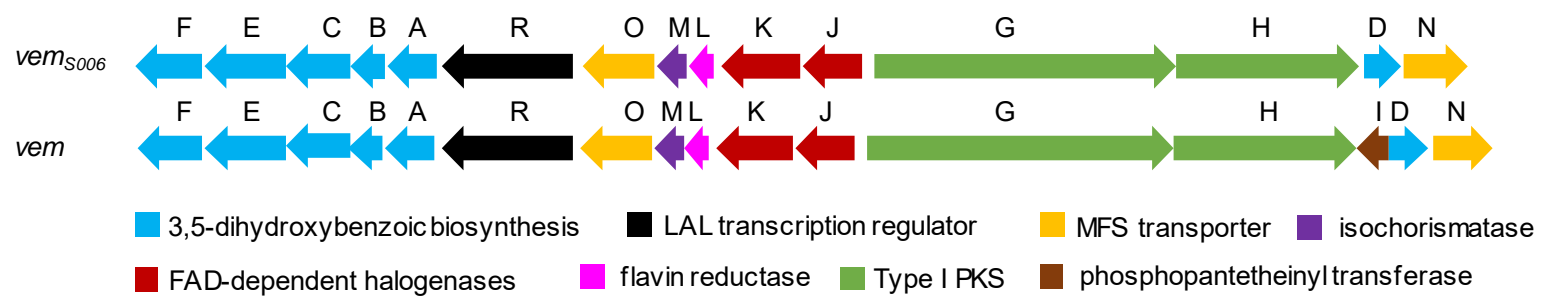

Figure S1. Genetic organization of vem gene cluster in Streptomyces sp. S006 (top) and Streptomyces venezuelae ATCC 10712 (bottom).

Table S3. Deduced functions of ORFs in the vem gene cluster.

\begin{tabular}{|c|c|c|c|c|}
\hline ORF & Amino acids & Proposed function & Identity/Similarity[\%] & Accession number \\
\hline VemA & 361 & type III polyketide synthase & $96 / 98$ & WP_031224837.1 \\
\hline VemB & 235 & $\begin{array}{l}\text { enoyl-CoA hydratase/isomerase } \\
\text { family protein }\end{array}$ & $85 / 91$ & WP_015031700.1 \\
\hline VemC & 454 & $\begin{array}{l}\text { enoyl-CoA hydratase/isomerase } \\
\text { family protein }\end{array}$ & $93 / 95$ & WP_031224838.1 \\
\hline VemD & 267 & enoyl-CoA hydratase & $92 / 97$ & WP_107461283.1 \\
\hline VemE & 569 & $\begin{array}{l}\text { thiamine pyrophosphate-binding } \\
\text { protein }\end{array}$ & $91 / 95$ & WP_064750866.1 \\
\hline VemF & 483 & benzaldehyde dehydrogenase & $92 / 95$ & WP_023546770.1 \\
\hline VemG & 2149 & type I polyketide synthase & $77 / 82$ & WP_053639873.1 \\
\hline VemH & 1310 & type I polyketide synthase & $92 / 94$ & WP_023546758.1 \\
\hline VemJ & 425 & $\begin{array}{l}\text { NAD }(\mathrm{P}) / \mathrm{FAD} \text {-dependent } \\
\text { oxidoreductase }\end{array}$ & $98 / 98$ & WP_023546760.1 \\
\hline VemK & 561 & FAD-dependent oxidoreductase & $97 / 98$ & WP_107461279.1 \\
\hline VemL & 175 & flavin reductase & $95 / 96$ & WP_023546762.1 \\
\hline VemM & 219 & isochorismatase & $90 / 92$ & WP_107461277.1 \\
\hline VemN & 457 & MFS transporter & $93 / 95$ & WP_078630273.1 \\
\hline VemO & 524 & MFS transporter & $93 / 95$ & WP_107461276.1 \\
\hline VemR & 931 & LAL family transcriptional regulator & $89 / 92$ & WP_023546765.1 \\
\hline
\end{tabular}




\subsection{Constitutive overexpression of the LAL gene vemR in vem cluster}

A

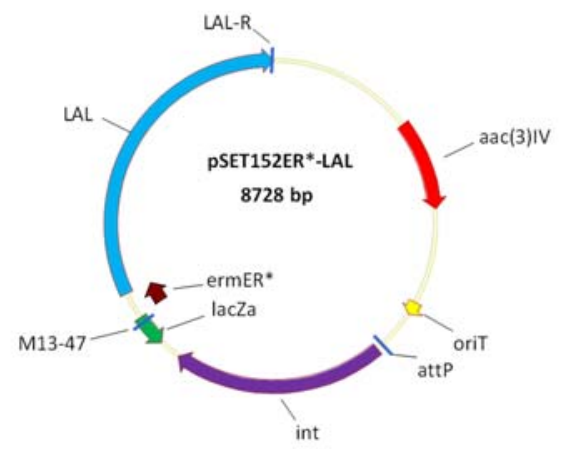

B

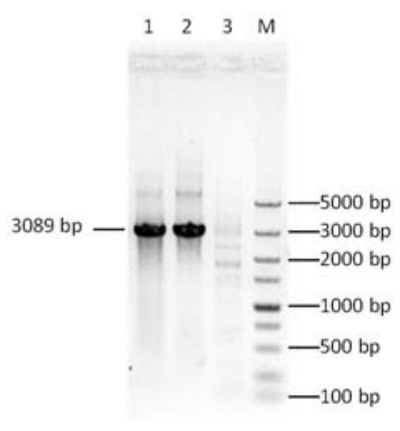

Figure S2. (A) Scheme of vemR overexpression plasmid. (B) PCR verification of the mutant S006-LAL. Line 1, the mutant S006-LAL; Line 2, the plasmid pSET152ER*-LAL; Line 3, S006 wild type; M, marker (DL5000, Takara)

\subsection{Production and analysis of the metabolites in mutants}

The wild type and the mutant strain S006-LAL were cultivated on $100 \mathrm{ml}$ Waksman, SFM or YMG agar for 9 days at $30{ }^{\circ} \mathrm{C}$. The agar was cut into small pieces and extracted with EtOAc/MeOH/AcOH 80:15:5 $(v / v / v)$ at room temperature overnight. The crude solution was concentrated under reduced pressure. The extract was dissolved in 1 $\mathrm{ml}$ methanol. A $10 \mu \mathrm{l}$ aliquot of each sample was analyzed by HPLC (YMC-UltraHT Pro C18 250×4.6 mm, $5 \mu \mathrm{m}$ ). HPLC conditions were as follows: solvent $\mathrm{A}$ : water with $0.1 \%$ formic acid, solvent $\mathrm{B}: \mathrm{CH}_{3} \mathrm{CN}(0.1 \%$ formic acid $)$; gradient: $0-5 \mathrm{~min}$, from 5 to $20 \% \mathrm{~B}$; $5-10 \mathrm{~min}$, from $20-40 \% \mathrm{~B} ; 10$ to $13 \mathrm{~min}$, from 40 to $70 \% \mathrm{~B} ; 13-17 \mathrm{~min}$, from 70 to $100 \% \mathrm{~B} ; 17-20 \mathrm{~min}, 100 \% \mathrm{~B} ; 20-23 \mathrm{~min}$, from $100-5 \% \mathrm{~B}$; flow rate $1 \mathrm{ml} / \mathrm{min}$, detected at $330 \mathrm{~nm} \mathrm{UV}$.

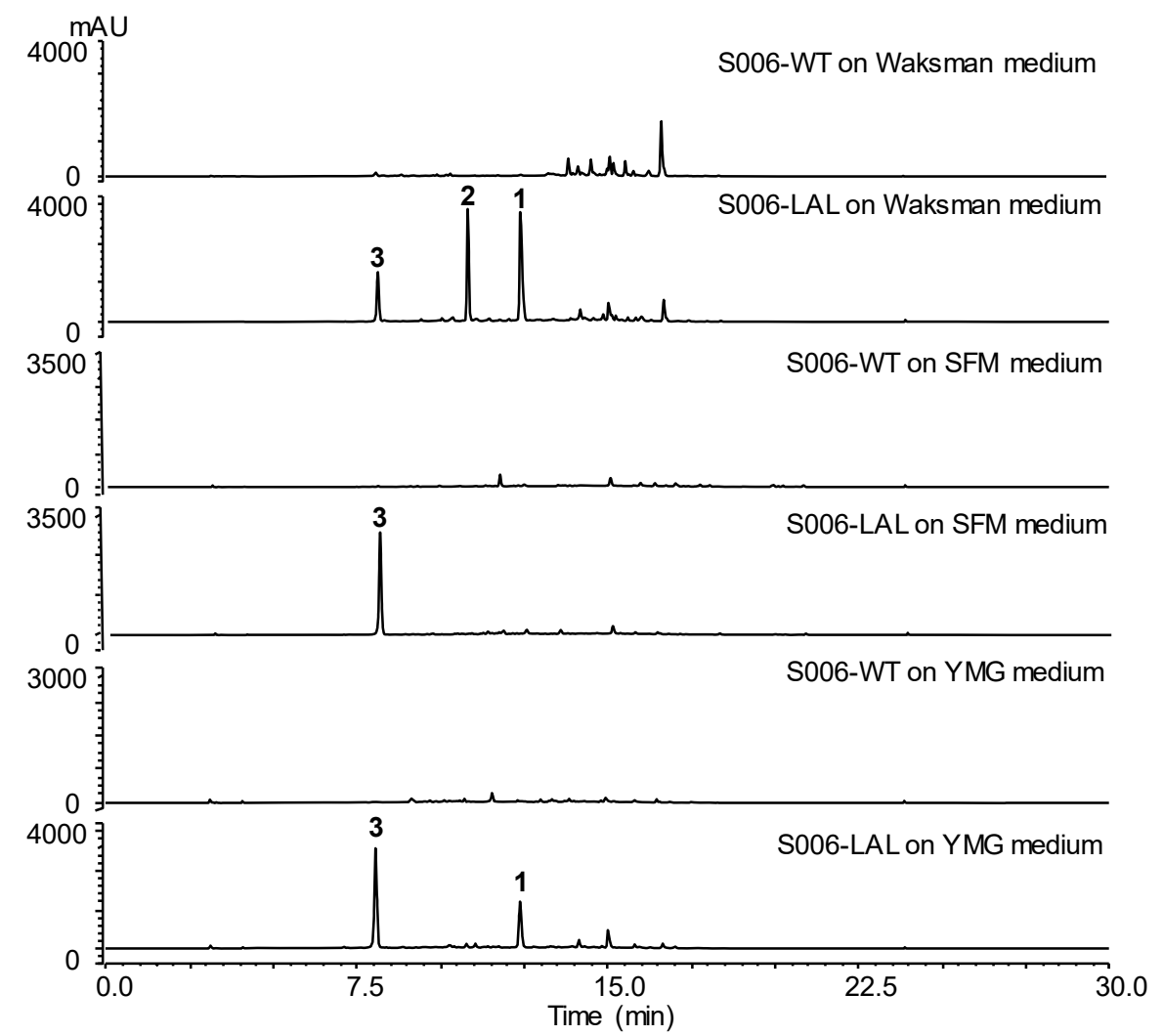

Figure S3. HPLC analysis of the metabolites of S006-WT and S006-LAL grown in different media. 


\subsection{Fermentation, isolation and structure elucidation of 1-3}

Fermentation $(10 \mathrm{~L})$ of S006-LAL was performed on Waksman agar $\left(9\right.$ days, $\left.30^{\circ} \mathrm{C}\right)$. The culture was cut into small pieces and extracted three times with $\mathrm{EtOAc} / \mathrm{MeOH} / \mathrm{AcOH}(80: 15: 5, v / v / v)$ at room temperature, and the solution was concentrated under low pressure at $35{ }^{\circ} \mathrm{C}$ and afterwards extracted with ethyl acetate. The crude extract was sequentially solvent partitioned into EtOAc-soluble and $\mathrm{H}_{2} \mathrm{O}$-soluble extract. The EtOAc extract was loaded on a Sephadex LH-20 column eluted with $\mathrm{MeOH}$ to obtain four fractions: Fr.1-4.

Fr.3 (893 mg) was purified using medium-pressure liquid chromatography (MPLC; 80 g RP-18 silica gel; with $\mathrm{MeOH}$ concentration at $30 \%, 50 \%, 70 \%$ and $100 \% ; 500 \mathrm{ml}$ each) to afford three subfractions: Fr.3a-3c. Fr.3a (454 $\mathrm{mg}$ ) was then purified by Sephadex LH-20 (60 g; in MeOH) and Fr.3a1-3a3 were obtained. Fr.3a1 were further purified by HPLC (eluted with $12 \%$ acetonitrile in $0.1 \%$ formic acid; flow rate $4 \mathrm{ml} / \mathrm{min}$; detected at $330 \mathrm{~nm} \mathrm{UV}$; YMC-Pack Pro C18 $250 \times 10 \mathrm{~mm}, 5 \mu \mathrm{m})$ to yield $3\left(t_{\mathrm{R}}=7.5 \mathrm{~min}, 13.5 \mathrm{mg}\right)$.

Fr.4 (190 mg) was purified using MPLC (80 g RP-18 silica gel; with MeOH concentration at 30\%, 35\%, 40\% and $100 \% ; 500 \mathrm{ml}$ each) to afford four subfractions: Fr.4a-4d. Fr.4c (120 mg) was subjected to Sephadex LH-20 (60 g; in $\mathrm{MeOH}$ ) and Fr.4c1-4c4 were obtained. Fr.4c2 were further purified by HPLC (eluted with $20 \%$ acetonitrile in $0.1 \%$ formic acid) to yield $2\left(t_{\mathrm{R}}=9.5 \mathrm{~min}, 4 \mathrm{mg}\right)$. Fr. $4 \mathrm{c} 3$ were purified by HPLC (eluted with $30 \%$ acetonitrile in $0.1 \%$ formic acid) to yield $\mathbf{1}\left(t_{\mathrm{R}}=6.6 \mathrm{~min}, 9 \mathrm{mg}\right)$.
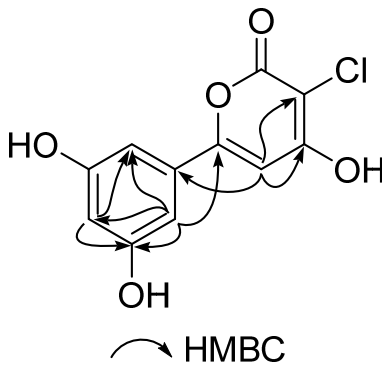

2-Cl venemycin (1)

Figure S4. The HMBC correlations of compound 1.

Table S4. The NMR data for 1-3 (At 400 and $100 \mathrm{MHz}, \delta$ in ppm, $J$ in $\mathrm{Hz}$ ).

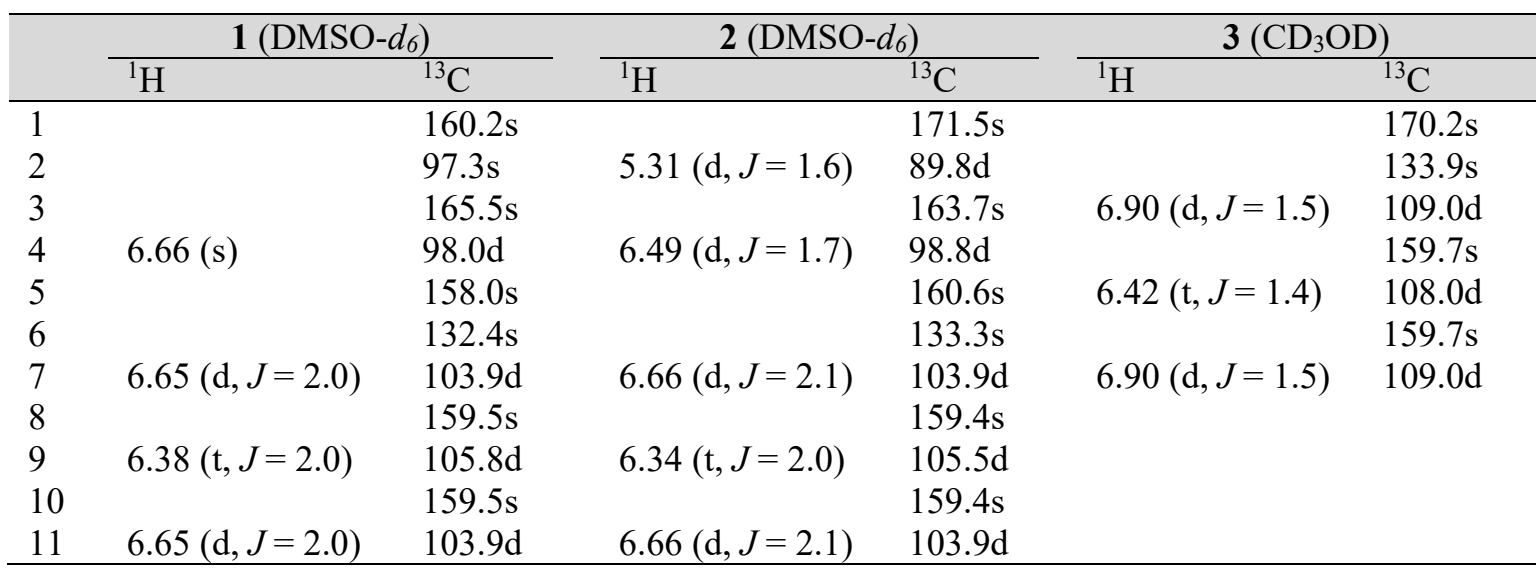




\subsection{Cloning, expression, and purification of VemJ, VemK and VemL}

For expression of vemJ, vemK and vemL in E. coli, they were amplified by PCR using genomic DNA of Streptomyces sp. S006 as a template with primer pairs of vemJF/vemJR, vemKF/vemKR, and vemLF/vemLR, respectively (Table S2). The resulting vemJ and vemK fragments were digested with NdeI and HindIII, and ligated to the NdeI/HindIII-digested pET28a to create pET28a-vemJ and pET28a-vemK, respectively. The vemL fragment was digested with NdeI and XhoI, and ligated to the NdeI/XhoI-digested pET28a to create pET28avemL. The three constructs were sequenced to verify the identity of the genes, and were subsequently introduced into E. coli BL21(DE3). Individual single colonies were inoculated in LB medium containing kanamycin (50 $\mu \mathrm{g} / \mathrm{ml}$ ) at $37^{\circ} \mathrm{C}$ to $\mathrm{OD}_{600}=0.5$ and then induced with $100 \mu \mathrm{M}$ isopropyl $\beta$-D-thiogalactopyranoside (IPTG) and grown for another $20 \mathrm{~h}$ at $16^{\circ} \mathrm{C}$. Protein purification was performed at $4{ }^{\circ} \mathrm{C}$. The induced cells were harvested by centrifugation (3000 g, $10 \mathrm{~min})$ and resuspended in lysis buffer $(25 \mathrm{mM}$ Tris-AcOH, pH 8.0, $100 \mathrm{mM} \mathrm{NaX}$ ( $\mathrm{X}$ for $\mathrm{F}, \mathrm{Cl}, \mathrm{Br}$ or I)). The cell suspension was sonicated on ice. The supernatant was collected by centrifugation $(16000 \mathrm{~g}, 20 \mathrm{~min})$ and filtered through a $0.45 \mu \mathrm{m}$ filter membrane before loading onto a Ni-NTA column (GE Healthcare, Ni Sepharose 6 Fast Flow). The His 6 -tagged proteins were eluted with an elution buffer (lysis buffer with $250 \mathrm{mM}$ imidazole). The purity of the proteins were analyzed by SDS-PAGE (Figure S5A) and the fractions containing the purified proteins were dialyzed against a buffer containing $25 \mathrm{mM}$ Tris- $\mathrm{AcOH}, \mathrm{pH} 8.0$, $100 \mathrm{mM} \mathrm{NaX}$ ( $\mathrm{X}$ for $\mathrm{F}, \mathrm{Cl}, \mathrm{Br}$ or I), and $10 \%$ glycerol. Finally, the protein preparation was frozen in liquid nitrogen and stored at $-80{ }^{\circ} \mathrm{C}$ until use.
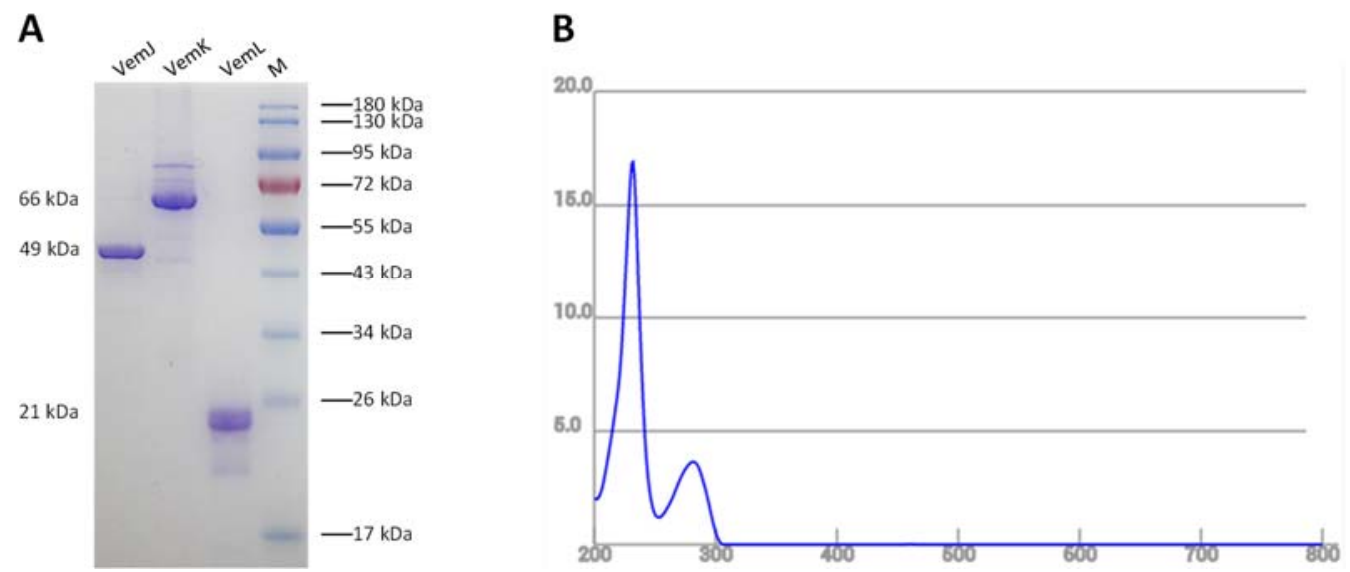

Figure S5. (A) SDS-PAGE analysis of halogenases VemJ and VemK, and flavin reductase VemL; (B) Ultraviolet absorption of VemK. 


\subsection{The flavin reductase activity of VemL}

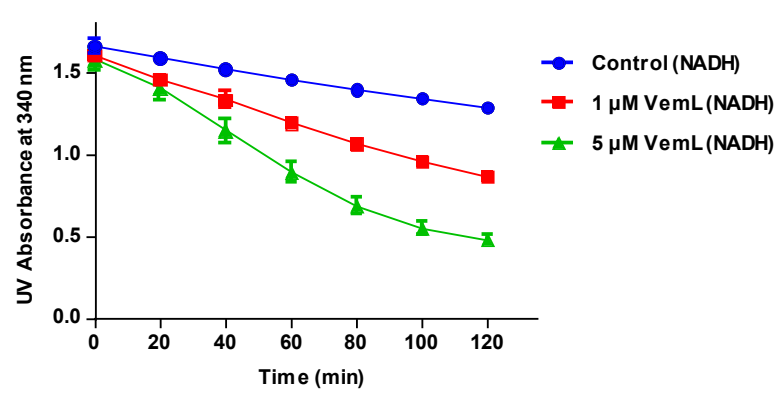

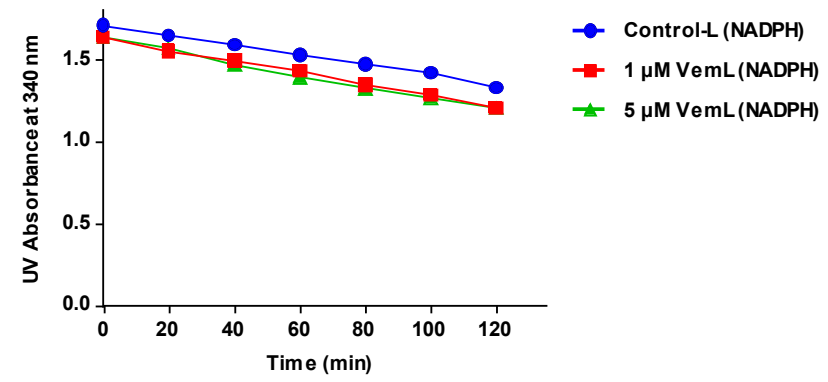

Figure S6. The flavin reductase activity of VemL for NADH (A) or NADPH (B). The reaction mixture contained $25 \mathrm{mM}$ Tris- $\mathrm{HCl}$ (pH 8.0), $0.4 \mathrm{mM}$ NAD(P)H, $0.2 \mathrm{mM} \mathrm{FAD}, 100 \mathrm{mM} \mathrm{NaCl}$ and VemL $(0 \mu \mathrm{M}, 1 \mu \mathrm{M}, 5 \mu \mathrm{M})$ and incubated at $30{ }^{\circ} \mathrm{C}$. The activity of VemL was determined by measuring the decrease in absorbance at $340 \mathrm{~nm}$ due to the oxidation of $\mathrm{NAD}(\mathrm{P}) \mathrm{H}$. 


\subsection{Enzyme assays for VemJ and VemK}
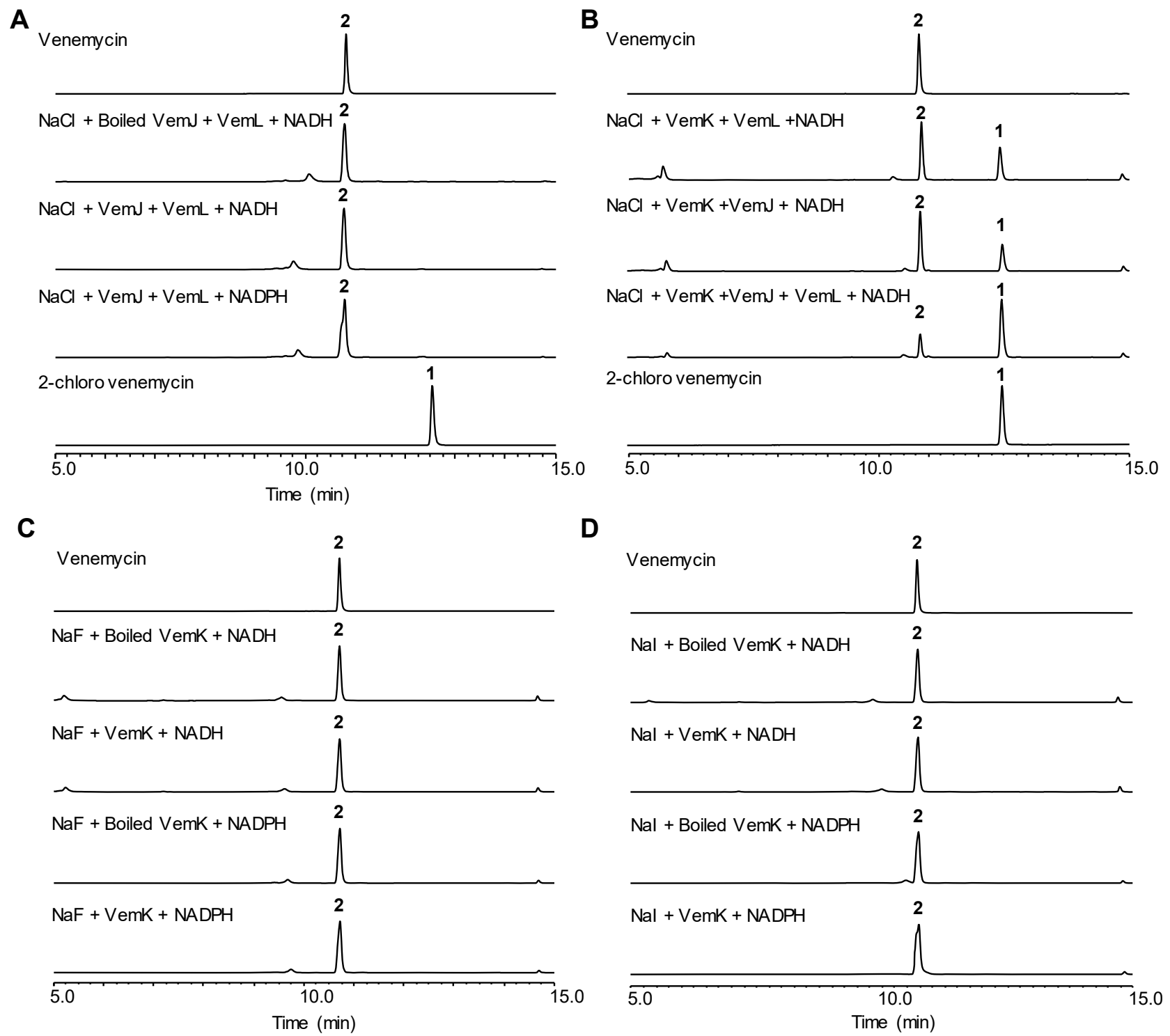

Figure S7. (A) HPLC analysis of the reaction mixture containing VemJ, VemL and $\mathrm{NaCl}$; (B) HPLC analysis of the reaction mixture containing various combination of $\mathrm{VemK}$, VemJ, VemL and $\mathrm{NaCl}$. The reaction was incubated for $2 \mathrm{~h}$ at $30^{\circ} \mathrm{C}$. (C) HPLC analysis of the reaction mixture containing VemK and NaF; (D) HPLC analysis of the reaction mixture containing VemK and NaI. HPLC conditions were as follows: solvent A: water with $0.1 \%$ formic acid, solvent $\mathrm{B}$ : $\mathrm{CH}_{3} \mathrm{CN}$ with $0.1 \%$ formic acid; gradient: $0-5 \mathrm{~min}$, from 5 to $20 \% \mathrm{~B} ; 5-10 \mathrm{~min}$, from 20 to $40 \% \mathrm{~B} ; 10$ to $13 \mathrm{~min}$, from 40 to $70 \% \mathrm{~B}$; $13-17 \mathrm{~min}$, from 70 to $100 \% \mathrm{~B} ; 17-20 \mathrm{~min}, 100 \% \mathrm{~B} ; 20-23 \mathrm{~min}$, from $100-5 \% \mathrm{~B}$; flow rate $1 \mathrm{ml} / \mathrm{min}$, detected at $330 \mathrm{~nm} \mathrm{UV}$. 


\subsection{Characterization of VemK}
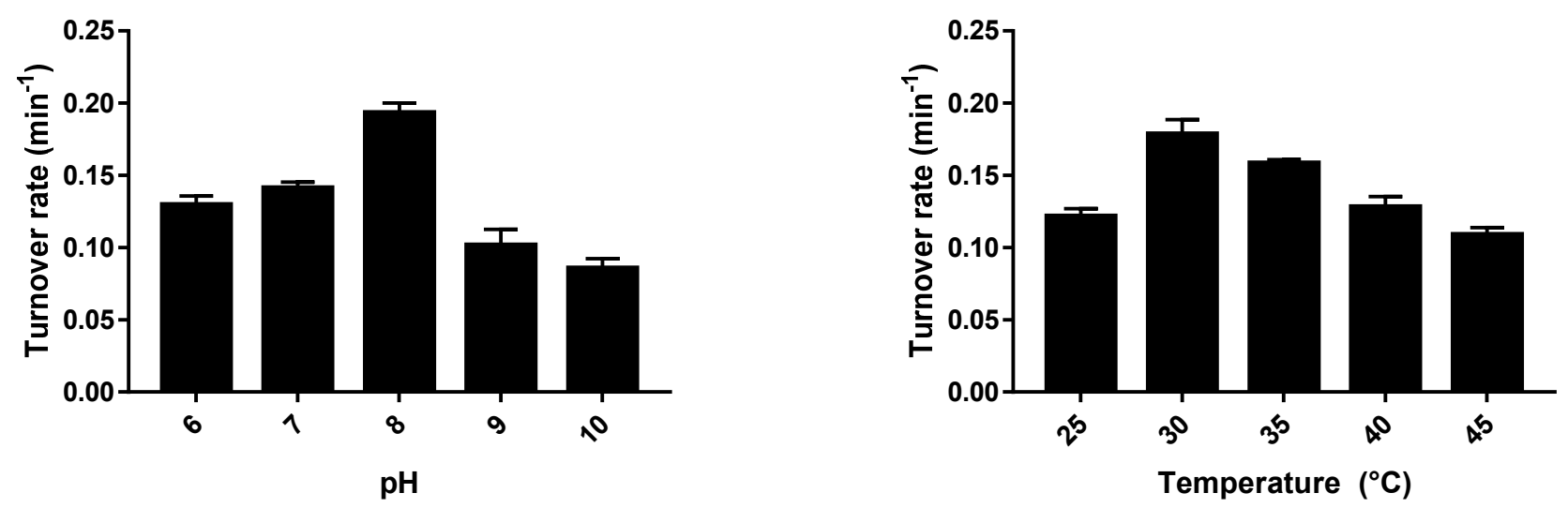

Figure S8. Characterization of VemK. (A) pH optimum for 1 production catalyzed by VemK. (B) Temperature optimum for 1 production catalyzed by VemK. The reactions were carried out in reaction mixture $(100 \mu 1,25$ $\mathrm{mM}$ Tris-HCl, $100 \mathrm{mM} \mathrm{NaCl}, 144 \mu \mathrm{M}$ 2, $5 \mathrm{mM}$ NADH, $0.1 \mathrm{mM} \mathrm{FAD}$, and $12 \mu \mathrm{M}$ VemK). The optimal pH was determined by incubating the mixture for $10 \mathrm{~min}$ at $30^{\circ} \mathrm{C}$ in $100 \mathrm{mM}$ Tris- $\mathrm{HCl}$ buffer at $\mathrm{pH} 6.0,7.0,8.0,9.0$, or 10.0. The optimal temperature for VemK activity was examined by incubating the mixture at $\mathrm{pH} 8.0$ for 10 $\min$ at $25,30,35,40$, or $45^{\circ} \mathrm{C}$. 


\subsection{Phylogenetic analysis of VemK}

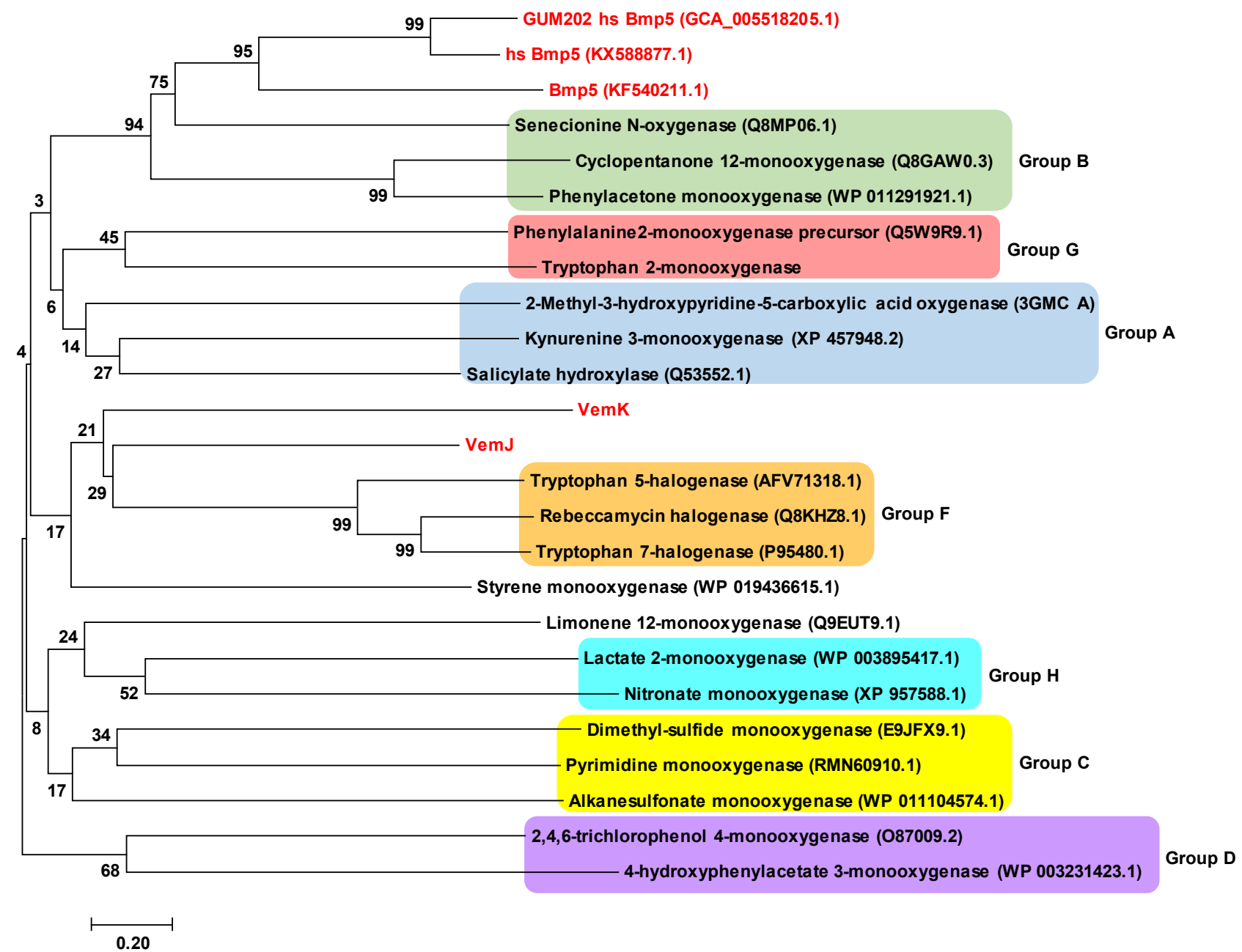

Figure S9. Phylogenetic analysis of VemK with flavin dependent monooxygenases. ${ }^{3}$ Similar sequences were aligned with ClustalW, and the tree shown was generated by using MEGA 7.0.26 software. 
1.11 Multiple alignment of VemK with other three single-component FDHs

VemK

Bmp5

hs_Bmp5

G hs_Bmp5

VemK

Bmp5

hs_Bmp5

G hs_Bmp5

VemK

Bmp5

hs_Bmp5

G hs_Bmp5

VemK

Bmp5

hs_Bmp5

$\mathrm{G}$ hs_Bmp5

VemK

Bmp5

hs_Bmp5

G hs_Bmp5

VemK

Bmp5

hs_Bmp5

G hs_Bmp5

VemK

Bmp5

hs_Bmp5

$\mathrm{G}$ hs Bmp5

VemK

Bmp5

hs_Bmp5

G hs_Bmp5

VemK

Bmp5

hs_Bmp5

G hs_Bmp5

VemK

Bmp5

hs_Bmp5

G hs_Bmp5

VemK

Bmp5

hs_Bmp5

G hs_Bmp5

VemK

Bmp5

hs_Bmp5

G hs Bmp5

VHGKNSASVAADRYDVAILGSGMAGGMLGAVLARNGVKTLIL-DAGTHP--RFAVG--ES

----------MRKKIAVIGAGLSGIAAIKQLT-DGGHEVVCFEKAESFGGVFADKKIYE -MLDCIVIGAGSGGLVT IKELLEQGVGEVVCLEQAEDVGGVFAN--TYD -MWDCIIIGSGPGGLVTTKELLERGVREVVCLEQGKEVGGIYTN--AYD $:: *: *$ * $\quad * \quad:: \quad: \quad:$ TIPYTSGMARLIAKRYDVPELKA--------LSNYKGTIEEVSPNCGQKQNFGFV-YHRE DLHLTISNYFMAYSDY-VPSQQKLKFWSKKEYVNYLGEYLAR-FELGQYIHYDHEVRKVE SLVLTSSATISMFSDFWIGDGNQHKFWTKDEVVDYWKKYAEQ-FGVLEHIRFGSKVVAVV NLVLTSSCTYSMFSDFWIGDGKQHEFWTKNEAVDYWKSYAKH-FDIEDKIRLNSQVVAVT

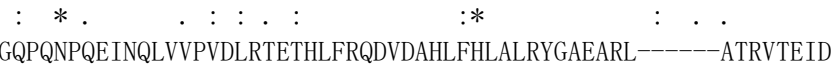
KQ------AGKWQV--TTKHGMAEQTDT----FDMVAVCSGHFQKPKMPELAGLDMFEGE E-----QGGEGWQV--QLASGENLLT-------KRVALAIGNNAIPKYPEWKEL-LTEVE PQDNKPQDNKGWQV--QLASGDILLS-------KRVALAIGNNSIPSYPQWKDL-LTEVE

* $\quad: *$ : * : * :

IDPDEGAVLRTEHGEEIRASYV-------VDGSGFRSPLAEKFDLRETPTRARTHSRCLF IE----------HSNDYRDKHKYAGKRVLCV GLGESS-A----D--ITSEISEVASKCIL YS----------HSQDYRNADRFAGKTVLAVGGGESG-A----D--IALEISRVASKCWV FS----------HSGGDKYVV----MH------------------------------YLSMWK *. :

THMIGVKPFDDSPTAQPHDQPSPWHHGTLHHVFDGGWLWVIPFDNHDKARNPLCSVGLTL SLRRYPAV---APRYMAFQ-------EDPYFTIDTSWLTSRIVN----------------K SLRNSAGW--IVPRRRGIN--------AADISTHRGVW------------------------G

DPRKYPKGDTPP--_-_-_--_EQEFEDFLKRF--_--PEIAWQFEGAKSVRPWVS-TGRL LPHRYHGGITKGIFTK-----------YVNSRNDHVRIRGEWLKKSGPSHHQAVTKNERL LPRDYGAVLTEAVNQAELSQKDPVYDTVVKLNQKVEAKKGIWGIFA--------TKNFSL -PTNILSNFVWGIYG--------TKTFSL

$$
\text { . * . } \quad \text {. * * }
$$

Q-----YSAETVVG---------------DRYCLTSHAAGFIDALYSRGLANTLELVNAL FRPIADGKVVPNIGGIVRFEKNAVVF---QDGTREEIDA----VVFCTGYQLSFPFLD-PKAIV-NHGCKVVGEIVKVEDGGRTLHTADGECLTNVDA----VVFSTGYKNAVSFLP-PKAIV-HYGCQVIGEILRVEDGGRTLIAADGEVLSNVDA----VVFCTGYKNQVSFLL--

$$
\text { :* } \quad: \quad \text {. } * \text {. : : * } * \text {. : }
$$

GWRLIAASRDGDWSKERFAHVEALQQGLF--DFHDDLVYSSFVGFGHYELWNAVNRTWML 416

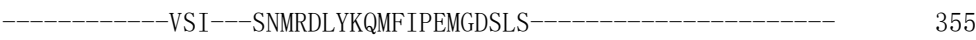

---------EELKQ---TDPRGLYKHMFHPKYQDKLV---------------------- 352

-DELKE---IDIRNLYKHMFHSKYRDKIV------------------------ 274

GTMSGNMMVEDAYYRYSESGDPDVFLEAERSGNPGSPLPISETFVRMGTL---------- 466

---_---_--_---_---_----FIGFVRP-QQGGIPVIAEMQCRYLSQLASGEKSLPP 390

-WIGWARP-NFGSQFPIMEMQARLFALICKGELALPA $\quad 387$

-WIGWARP-AFGSQFPIMEMQARFLALICTGEKTLPA 309

$: \quad * \quad * \quad * * *$ :

TRELCEAVEAGTLEPGVAAARIHEYIQKEVDFIAHADKFGLPENRCFNMT 516

LSEMVDIIKYDTEHWQTEYKIT-PHVASLVNYCHYMDSMAKLVGC-----_---_----- 434

PVEMEKVTCIDRATYLEQFENNAHQVRSLVDYHRYIDDMASLIGC---------------- 432

SSEMEEVASRDREKYLEQLEHNAERIRSLVDYHIYMDDLADLIGC---------------- 354

--_--MPEIPS-LFKDPLLRVKLLHNPQFAAQYRL--DGPNKMTHTARSFLLGFPNISSW 486

-----EPPLWQYFFLHPRIWLRMVYGAIQSTQFRL--RGPGNKESLARELLMKLPVSKPT 485

-----KPPLWKYFFLHPRLWLRMVYGATQATQFRL--RGPGQKEALARELIAKLPVAPFN 407

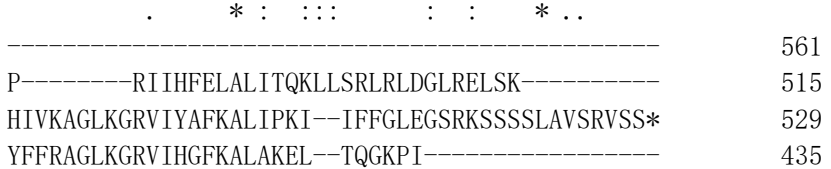

Figure S10. Multiple alignment of the amino acid sequences of VemK, Bmp5, hs_Bmp5, and partial GUM202 hs_Bmp5 (G hs_Bmp5) using Clustal Omega. The nicotinamide binding sequence motifs were shown in red box. 


\subsection{Homologous modeling of VemK and docking with NADH}

3D structure prediction of VemK was achieved by using I-tasser (https://zhanglab.ccmb.med.umich.edu/I-TASSER) server and Phyre2 (http://www.sbg.bio.ic.ac.uk/phyre2/html/page.cgi?id=index) server. The resulting VemK models were submitted onto swissdock (http://www.swissdock.ch/) to predict conserved amino acids which interacted with NADH.

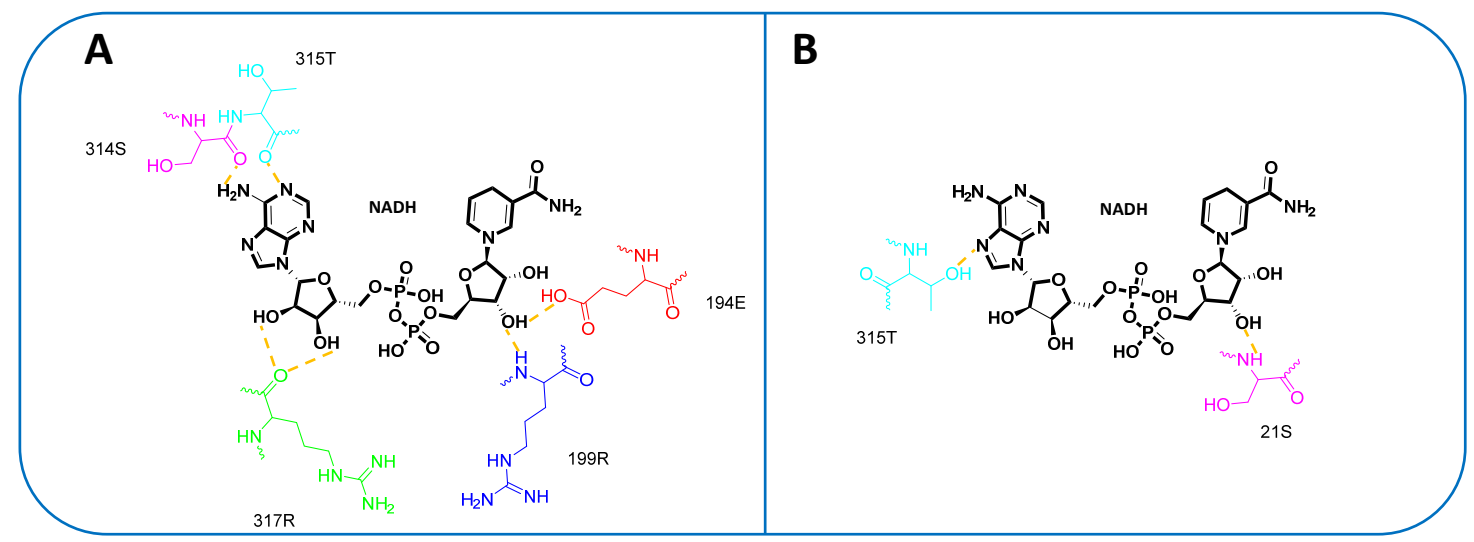

Figure S11. Docking scheme of NADH and protein models constructed by I-tasser (A) and Phyre 2 (B). 


\subsection{Point-mutation of VemK and purification of VemK mutants}

Taking S21A for example. Mutation was introduced into primers 21F (P3) and 21R (P2). PCR products using primers VemK-F2 (P1)/21R (P2) and VemK-R2 (P4)/21F (P3) were cloned into NdeI/HindIII digested pET28a by Gibson assembly. The resulting plasmid was verified by sequencing and transformed to E. coli B121(DE3). Individual single colonies were inoculated in LB medium containing kanamycin $(50 \mu \mathrm{g} / \mathrm{ml})$ at $37^{\circ} \mathrm{C}$ to $\mathrm{OD}_{600}=0.5$ and then induced with $100 \mu \mathrm{M}$ IPTG and grown for another $20 \mathrm{~h}$ at $16{ }^{\circ} \mathrm{C}$. The induced cells were harvested by centrifugation $(3000 \mathrm{~g}, 10 \mathrm{~min})$ and resuspended in lysis buffer (25 mM Tris- $\mathrm{HCl}, \mathrm{pH} 8.0,100 \mathrm{mM} \mathrm{NaCl})$. The cell suspension was sonicated on ice. The supernatant was collected by centrifugation (16000 g, $20 \mathrm{~min})$ and filtered through a $0.45 \mu \mathrm{m}$ filter membrane before loading onto a Ni-NTA column. The His 6 -tagged proteins were eluted with an elution buffer (lysis buffer with $250 \mathrm{mM}$ imidazole). The purity of the proteins were analyzed by SDS-PAGE (Figure 3A) and the fractions containing the purified proteins were dialyzed against a buffer containing $25 \mathrm{mM}$ Tris- $\mathrm{HCl}(\mathrm{pH} 8.0), 100 \mathrm{mM} \mathrm{NaCl}$, and $10 \%$ glycerol. Finally, the enzyme was frozen in liquid nitrogen and stored at $-80{ }^{\circ} \mathrm{C}$ until use.

A

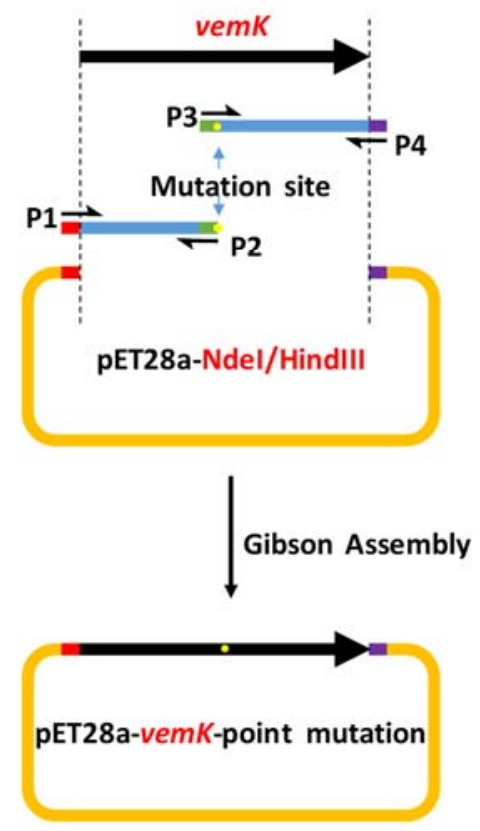

B
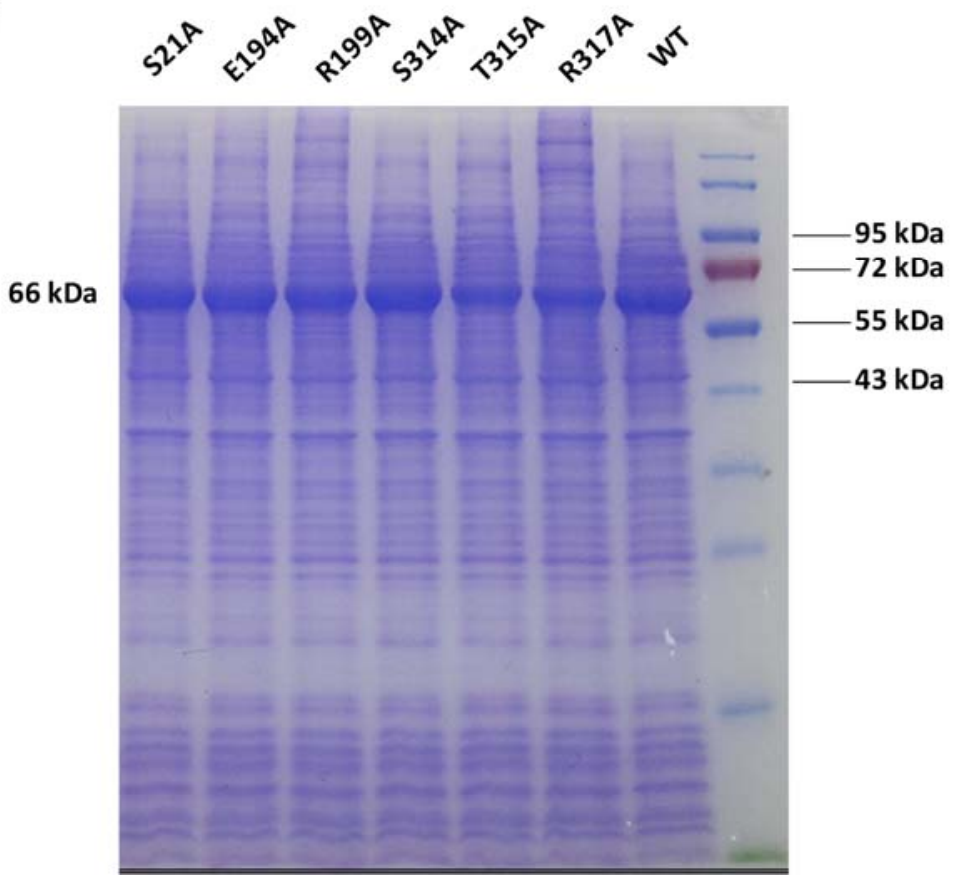

Figure S12. (A) Scheme of the construction of point-mutated vemK. (B) SDS-PAGE analysis of the expression of VemK and various mutants. 
2. NMR and HR ESIMS spectra of compounds 1-3

曹

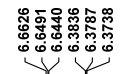

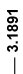<smiles>O=c1oc(-c2cc(O)cc(O)c2)cc(O)c1Cl</smiles>

venemycin B (1)

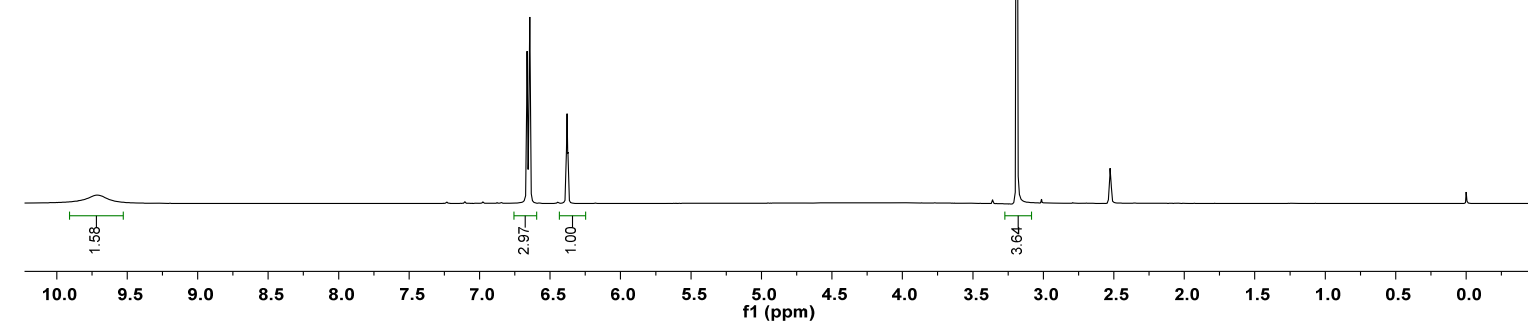

Figure S13. The ${ }^{1} \mathrm{H}$ NMR (400 MHz) spectrum of 1 in DMSO- $d_{6}$.

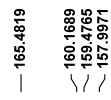

嵒

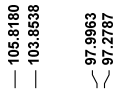

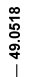<smiles>O=c1oc(-c2cc(O)cc(O)c2)cc(O)c1Cl</smiles>

venemycin $B(1)$

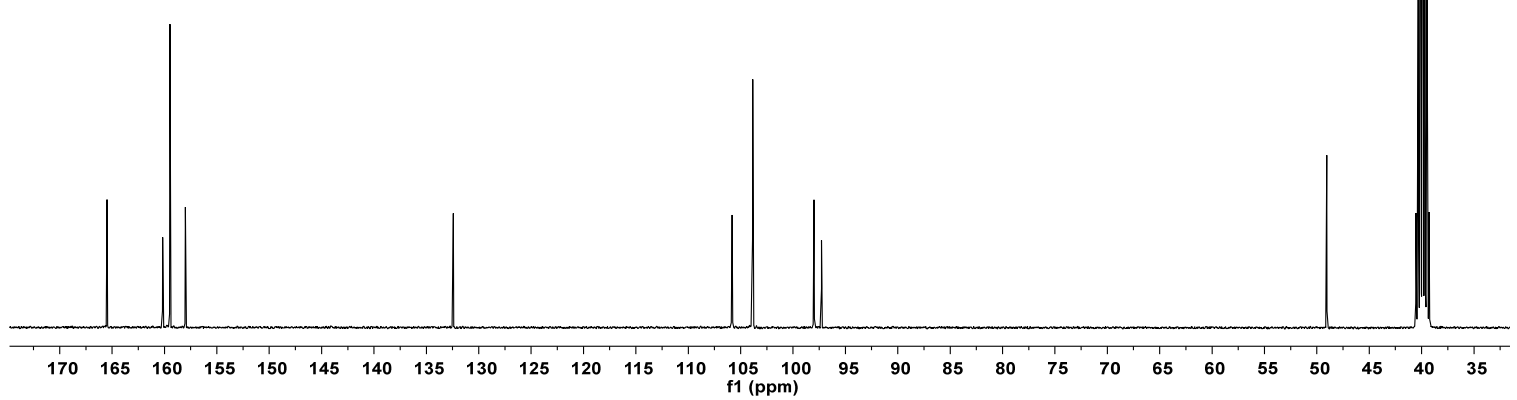

Figure S14. The ${ }^{13} \mathrm{C}$ NMR $(100 \mathrm{MHz})$ spectrum of 1 in DMSO- $d_{6}$. 


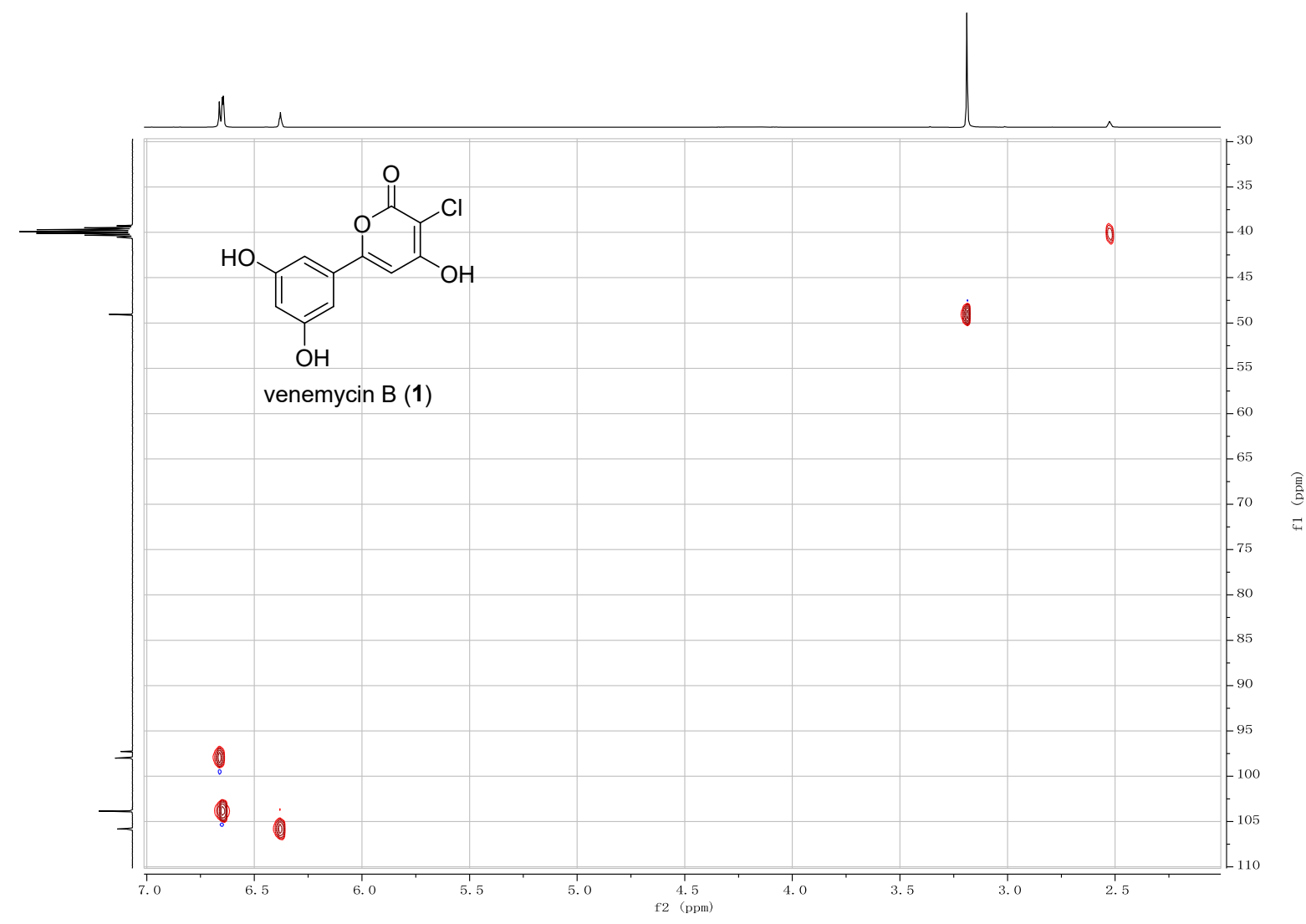

Figure S15. The HSQC spectrum of 1 in DMSO- $d_{6}$.

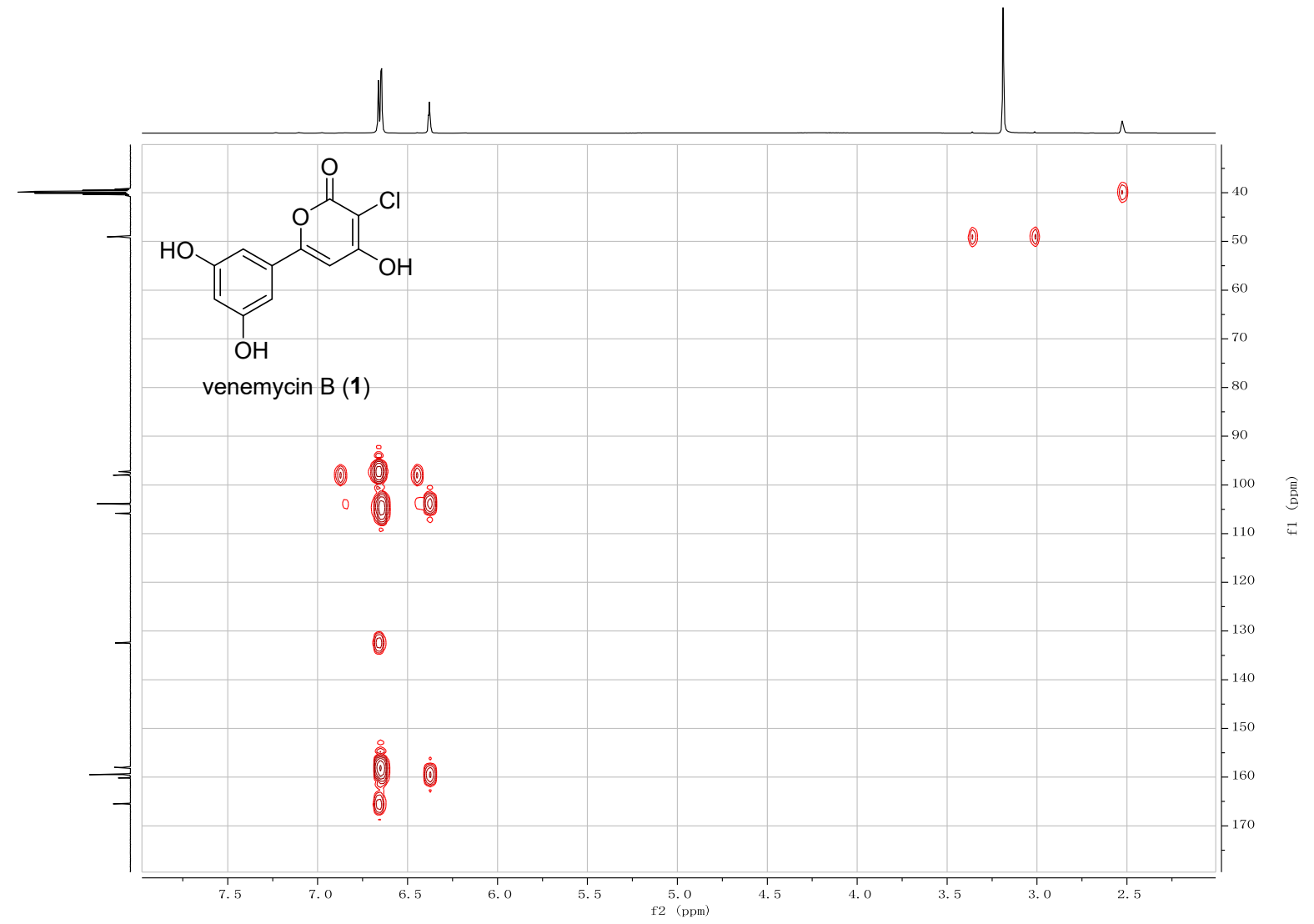

Figure S16. The HMBC spectrum of 1 in DMSO- $d_{6}$. 
S6GC2-IuxR \#1528 AV: 1 NL: 6.25E7

T: FTMS + p ESI Full ms [200.00-1000.00]

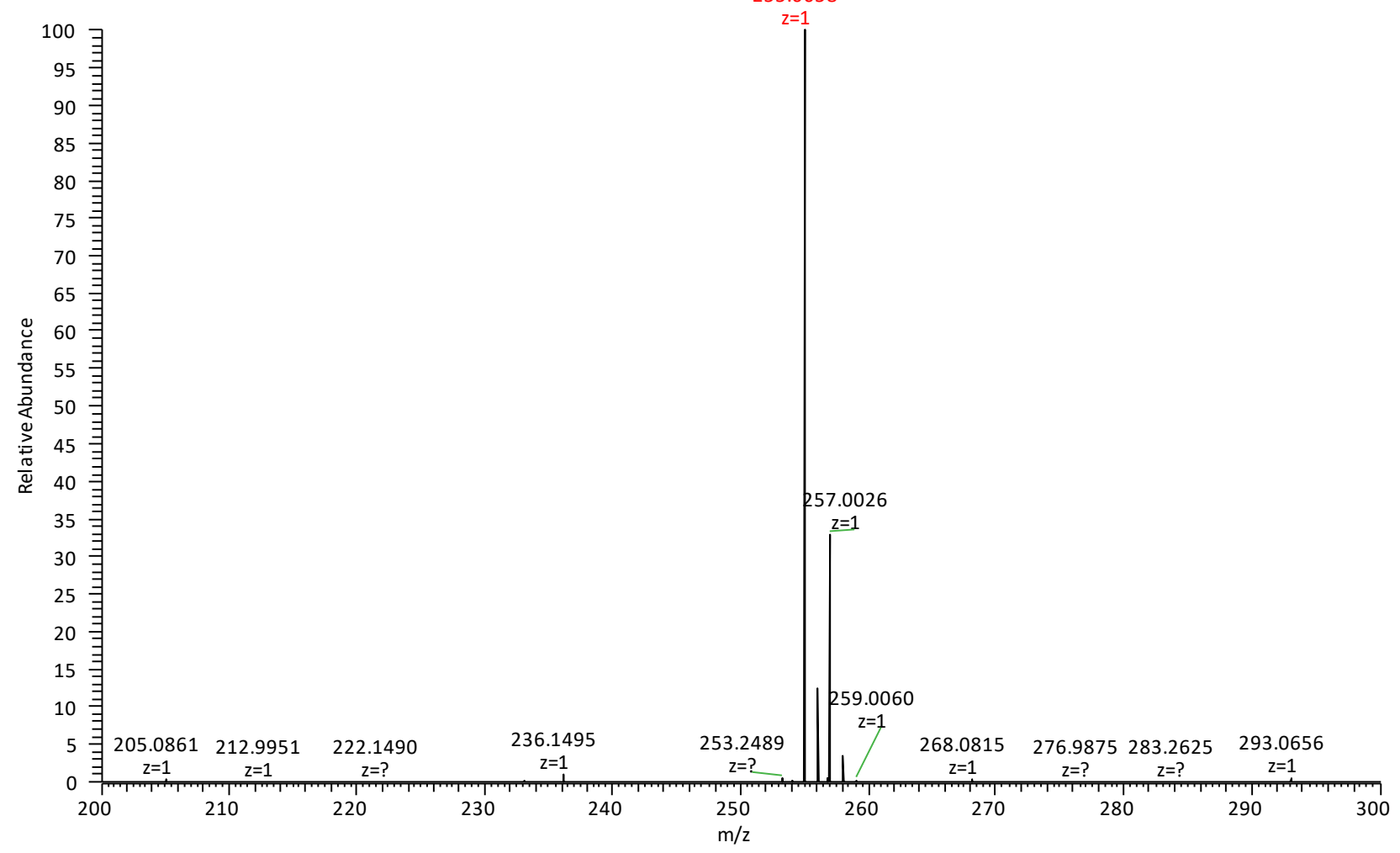

Figure S17. The HRESI mass spectrum of $\mathbf{1}$.
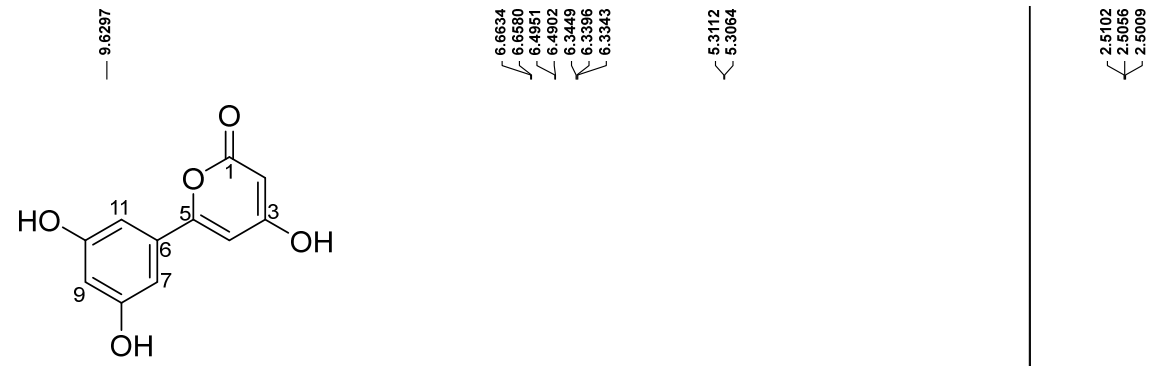

venemycin A (2)

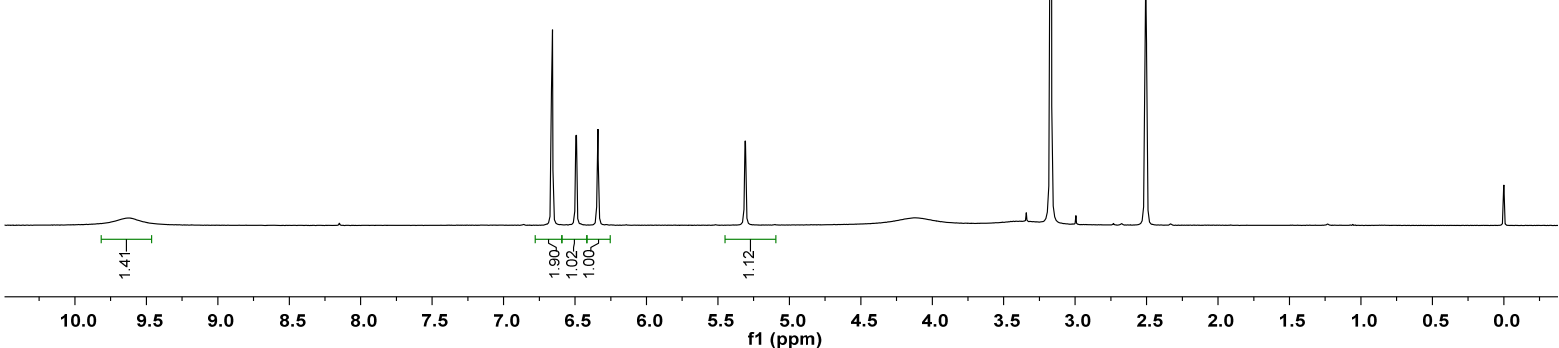

Figure S18. The ${ }^{1} \mathrm{H}$ NMR (400 MHz) spectrum of 2 in DMSO- $d_{6}$. 
<smiles></smiles>

venemycin $\mathrm{A}(\mathbf{2})$

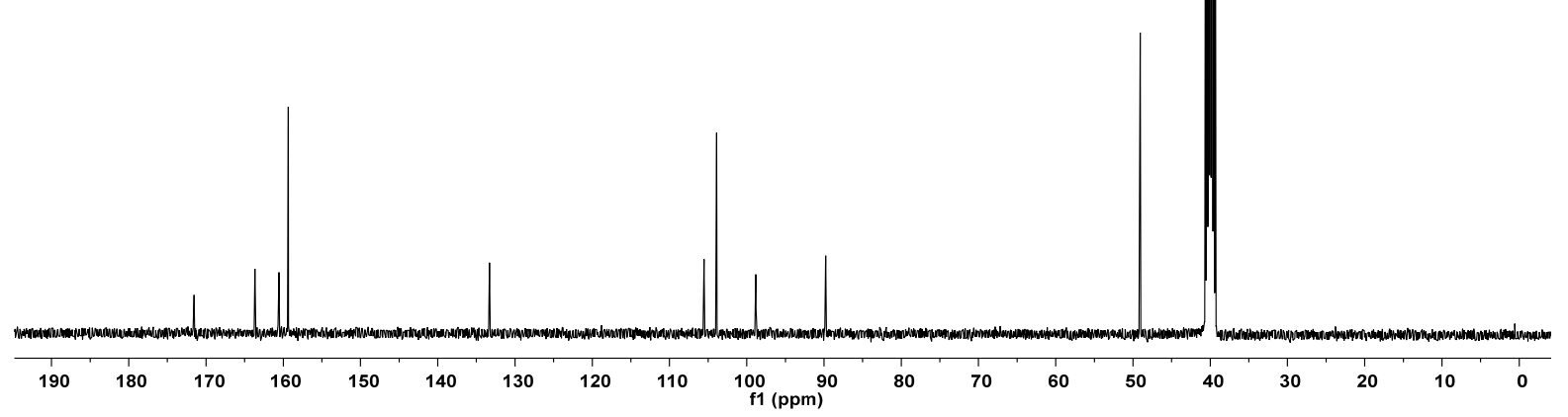

Figure S19. The ${ }^{13} \mathrm{C}$ NMR $(100 \mathrm{MHz})$ spectrum of $\mathbf{2}$ in DMSO- $d_{6}$.

S6GC2-luxR \#1218 AV: $1 \quad$ NL: 4.99E5
T: FTMS + p ESI Full ms [200.00-1000.00]

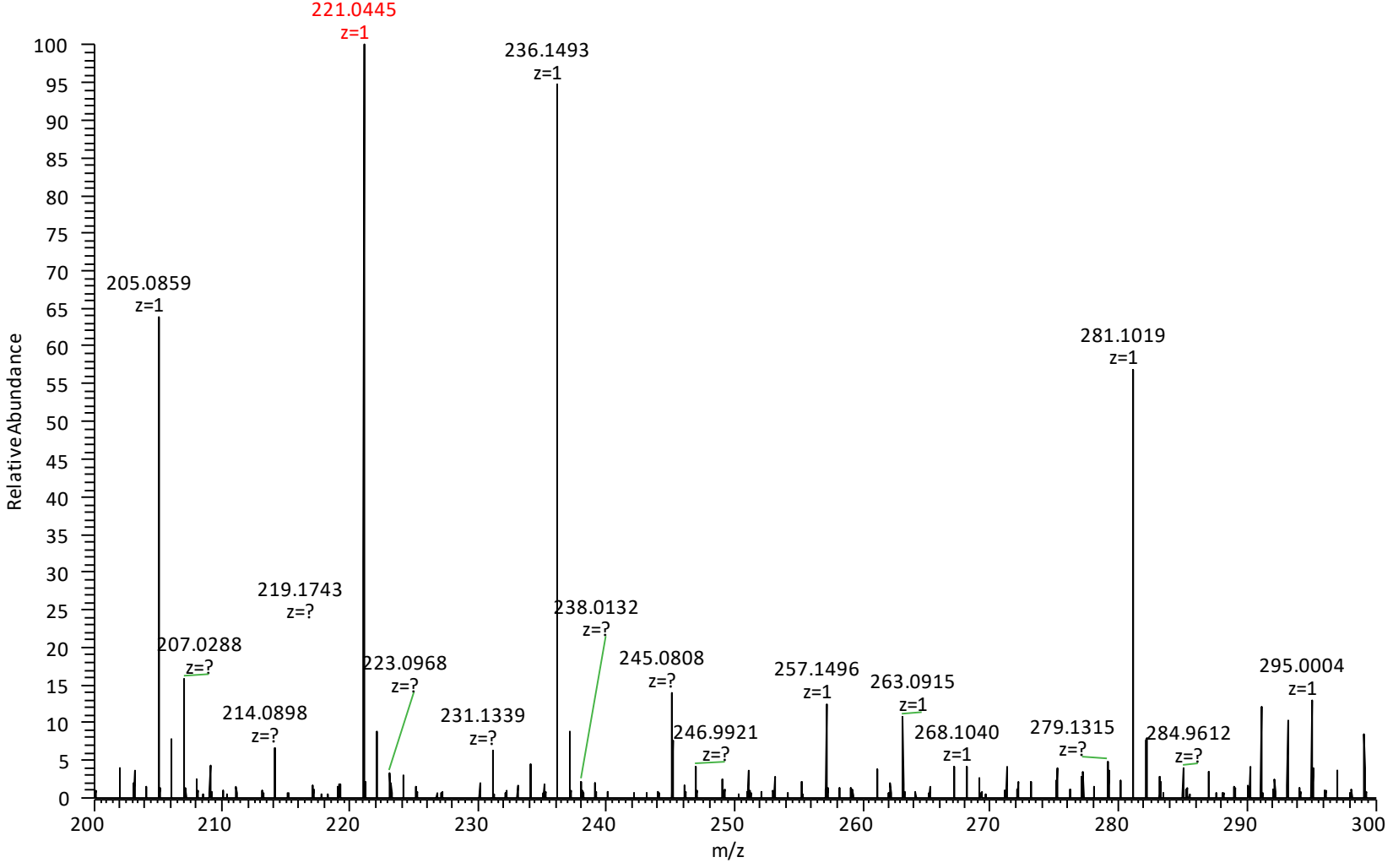

Figure S20. The HRESI mass spectrum of 2. 


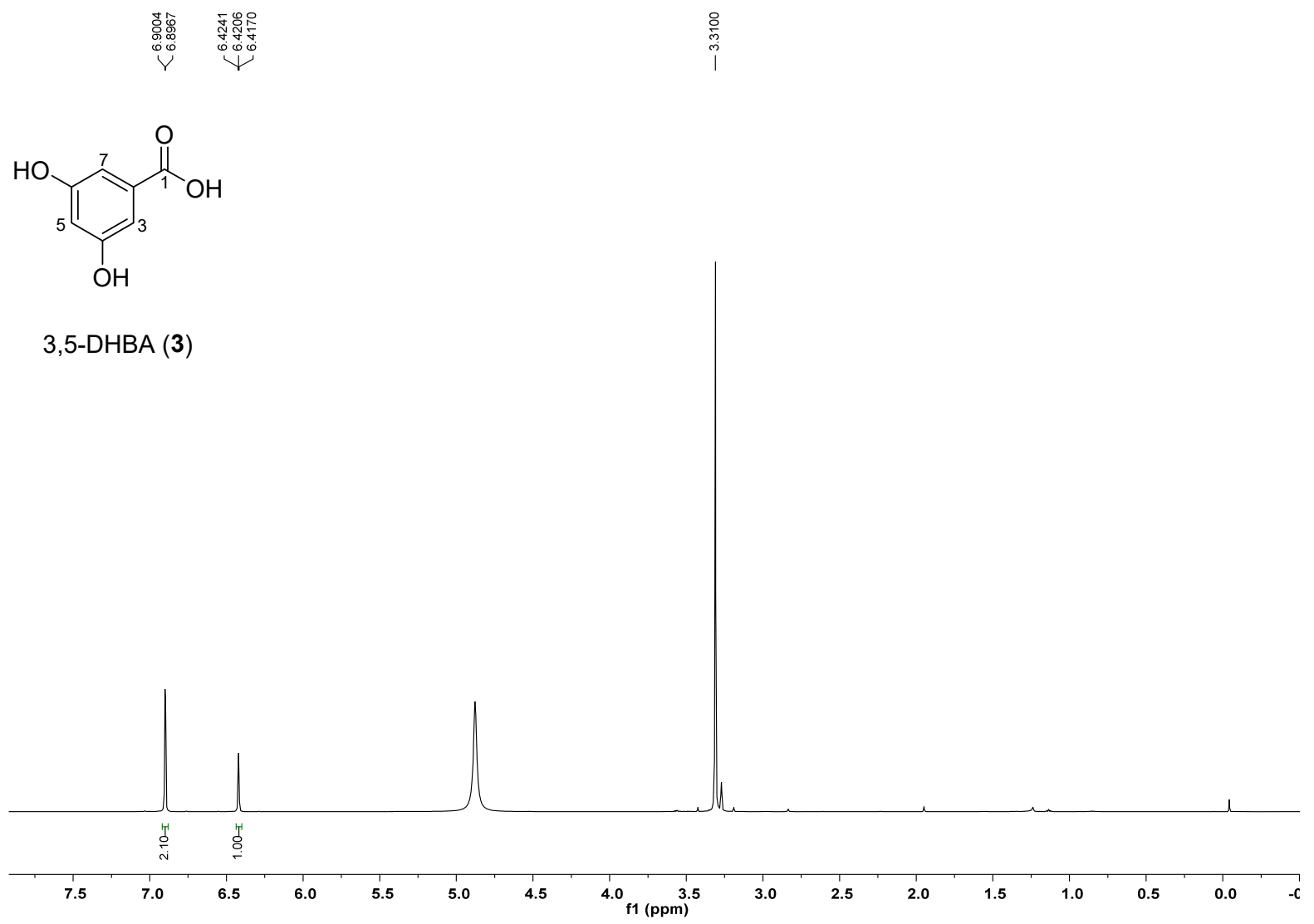

Figure S21. The ${ }^{1} \mathrm{H}$ NMR (400 MHz) spectrum of 3 in $\mathrm{CD}_{3} \mathrm{OD}$.

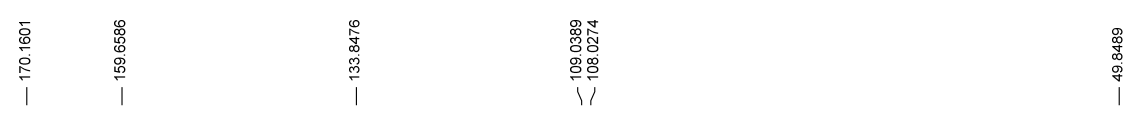<smiles>O=C(O)c1cc(O)cc(O)c1</smiles>

3,5-DHBA (3)

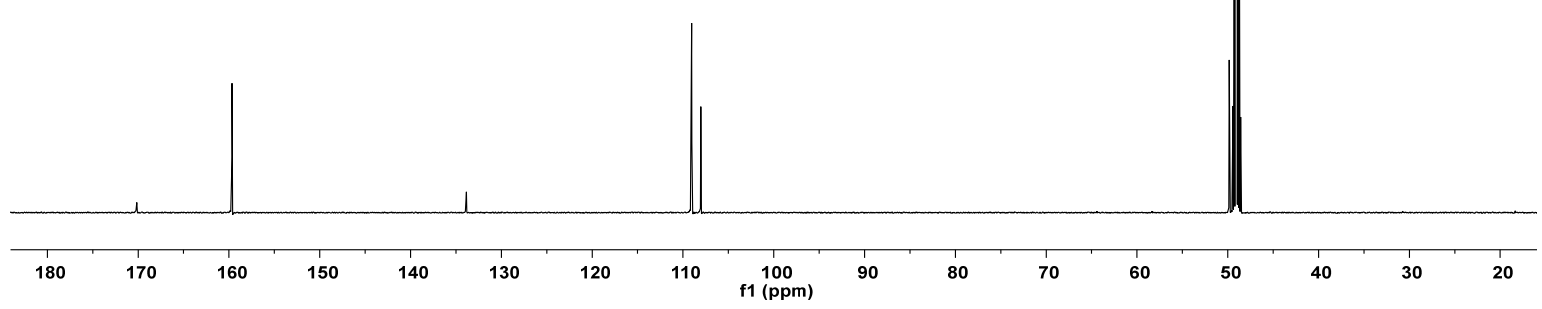

Figure S22. The ${ }^{13} \mathrm{C}$ NMR $(100 \mathrm{MHz})$ spectrum of $\mathbf{3}$ in $\mathrm{CD}_{3} \mathrm{OD}$. 


\section{References}

(1) Paget, M. S. B., Chamberlin, L., Atrih, A., Foster, S. J., and Buttner, M. J. (1999) Evidence that the extracytoplasmic function sigma factor sigma(E) is required for normal cell wall structure in Streptomyces coelicolor A3(2), J. Bacteriol. 181, 204-211.

(2) Luzhetskii, A. N., Ostash, B. E., and Fedorenko, V. A. (2001) Intergeneric conjugation Escherichia coli-Streptomyces globisporus 1912 using integrative plasmid pSET152 and its derivatives, Russ. J. Genet. 37, 1123-1129.

(3) Huijbers, M. M., Montersino, S., Westphal, A. H., Tischler, D., and van Berkel, W. J. (2014) Flavin dependent monooxygenases, Arch. Biochem. Biophys. 544, 2-17. 